\title{
Review Article \\ The Androgen Receptor Bridges Stem Cell-Associated Signaling Nodes in Prostate Stem Cells
}

\author{
Alastair H. Davies ${ }^{1}$ and Amina Zoubeidi ${ }^{1,2}$ \\ ${ }^{1}$ Vancouver Prostate Centre, Vancouver, BC, Canada V6H $3 Z 6$ \\ ${ }^{2}$ Department of Urologic Sciences, Faculty of Medicine, University of British Columbia, Vancouver, BC, Canada V6H $3 Z 6$
}

Correspondence should be addressed to Amina Zoubeidi; azoubeidi@prostatecentre.com

Received 30 September 2015; Revised 4 December 2015; Accepted 13 December 2015

Academic Editor: $\mathrm{Hu} \mathrm{Li}$

Copyright (C) 2016 A. H. Davies and A. Zoubeidi. This is an open access article distributed under the Creative Commons Attribution License, which permits unrestricted use, distribution, and reproduction in any medium, provided the original work is properly cited.

\begin{abstract}
The therapeutic potential of stem cells relies on dissecting the complex signaling networks that are thought to regulate their pluripotency and self-renewal. Until recently, attention has focused almost exclusively on a small set of "core" transcription factors for maintaining the stem cell state. It is now clear that stem cell regulatory networks are far more complex. In this review, we examine the role of the androgen receptor (AR) in coordinating interactions between signaling nodes that govern the balance of cell fate decisions in prostate stem cells.
\end{abstract}

\section{Introduction}

Stem cells, characterized by their ability to self-renew (divide and create additional stem cells) and generate differentiated functional cell types, have been derived from the embryo as well as various adult organs [1]. It is customary to classify stem cells into two major types according to their developmental potential: embryonic stem cells (ESCs) and somatic stem cells. ESCs are pluripotent, self-renewing cells localized to the inner cell mass of the developing blastocyst that are capable of generating all cell types of the body. As development proceeds, pluripotent ESCs disappear as more restricted (multipotent) somatic stem cells, such as haematopoietic stem cells and neural stem cells, that can only give rise to cell types within a particular lineage. Although the privilege of differentiating into any of the hundreds of cell types in the human body is reserved for the ESCs, adult somatic stem cells residing within an organ or tissue nevertheless retain some characteristics of their early ESC counterparts, including the capacity to self-renew while keeping their repertoire of differentiation programs on hold.

Deciphering the regulatory circuitry underlying stem cell pluripotency and self-renewal is an important key to understanding both normal and, in the case of cancer, abnormal development. Here, we review the recent advances that demonstrate the presence and involvement of the androgen receptor (AR) in both normal stem cells and cancer stem cells (CSCs), particularly those associated with the prostate. We will discuss how the AR fits into the molecular circuitry that maintains the pluripotent and self-renewal state. The role of the stem cell niche in regulating the AR will be analyzed, together with the clinical implications.

\section{The AR as a Regulator of the Stem Cell State}

The AR is a ligand-inducible transcription factor that in response to androgens (namely, testosterone and $5 \alpha$-dihydrotestosterone) dimerizes, translocates to the nucleus, and binds to androgen response elements (AREs) in the promoter region of target genes. Subsequent interaction with cofactors allows the AR complex to stimulate or inhibit gene transcription [2]. The AR is expressed in various tissues [3] and has been linked to several diseases, most notably prostate cancer [4]. While classically viewed as a driver of cell growth and survival, emerging evidence suggests that stem cells can be influenced by androgen and AR signals both in vitro and in vivo (Table 1). Thus, the AR may serve a currently underappreciated role in shaping the properties and defining the potential of stem cells. 
TABLE 1: The effect of androgens and/or AR expression on stem cell populations.

\begin{tabular}{llll}
\hline Stem cell type & Effect of AR/androgen & Effect of AR inhibition & References \\
\hline $\begin{array}{l}\text { Embryonic stem } \\
\text { cell }\end{array}$ & Cardiomyocyte differentiation & $\begin{array}{l}\text { Enhanced self-renewal } \\
\text { Increased proliferation }\end{array}$ & $\begin{array}{l}\text { Expansion of MEPs } \\
\text { Neutropenia }\end{array}$ \\
\hline $\begin{array}{l}\text { Haematopoietic } \\
\text { stem cell }\end{array}$ & $\begin{array}{l}\text { Erythropoiesis } \\
\text { Neutrophil differentiation }\end{array}$ & $\begin{array}{l}\text { Enhanced self-renewal } \\
\text { Enhanced migratory ability }\end{array}$ \\
\hline $\begin{array}{l}\text { Mesenchymal } \\
\text { stem cell }\end{array}$ & $\begin{array}{l}\text { Reduced self-renewal } \\
\text { Myogenic differentiation }\end{array}$ & Osteogenic differentiation & Increased proliferation \\
\hline Neural stem cell & Decreased proliferation & Enhanced self-renewal \\
\hline Prostate stem cell & Prostate epithelial differentiation & $\begin{array}{l}\text { Enhanced self-renewal } \\
\text { Expansion of CSC pool }\end{array}$ \\
\hline Prostate CSC & Reduced self-renewal & {$[124]$} \\
\hline
\end{tabular}

AR, androgen receptor; CSC, cancer stem cell; MEP, megakaryocyte-erythroid progenitor.

2.1. AR in Embryonic Stem Cells. Within the last decade several advances have made it possible to recapitulate in ESC cultures the key events that regulate lineage commitment in the embryo [5]. Manipulation of the AR axis in ESCs revealed that it acts as a negative regulator of the stem cell state. As ESCs begin to differentiate, AR levels rise in a stagedependent manner [6], suggesting that it may be functioning to suppress the stem cell phenotype. This hypothesis was confirmed by treating ESC cultures with steroid hormones in vitro. In particular, testosterone treatment efficiently stimulated ESC differentiation into cardiac mesoderm and, in turn, functional cardiomyocytes [7, 8]. Conversely, treating ESCs with nilutamide, an antiandrogen that inhibits AR activity, increased proliferation and enhanced self-renewal capacity [9].

2.2. AR in Prostate Stem Cells. Although cell diversification is largely complete at birth, organs must possess a mechanism to replenish cells as they die, by either normal wear and tear (homeostasis) or injury. To accomplish this feat, many developing organs set aside life-long reservoirs of somatic stem cells that retain some of the versatile characteristics of ESCs, such as capacity for self-renewal.

The classic androgen ablation and replacement experiments demonstrated that the prostate epithelia possess extensive regenerative capacity thus providing the earliest evidence for the existence of prostate stem cells [10]. More recent studies, utilizing specific cell surface markers and genetic lineage tracing approaches, have produced direct evidence for prostate stem cells. Correlative and in vitro experiments infer that prostate stem cells reside within the basal cell layer as basal cells not only are slow cycling and express many stem cell associated genes such as telomerase, bcl-2, and p63, but also have low level of the AR [11-13]. On the other hand, we recently learned from the study of Wang et al. a small subset of luminal cells that survive castration (termed CARNs for castration-resistant Nkx3.1-expressing cells) can self-renew in vivo and regenerate a prostate in renal grafts [14]. It is important to note that despite a luminal phenotype, the origin of CARN cells is unknown and it is possible that basal cells adapt a CARN cell phenotype in castrated mice.
Despite these complexities, the overwhelming consensus is that prostate stem cells have a basal origin. For instance, prospectively purified Lin-/Sca-1+/CD49f+ basal cells can establish spheres and colonies in vitro as well as regenerate prostate ducts in renal grafts [15]. Notably, the expression of the AR was found to be very low in these cells. In another study, a single Lin-/Sca-1+/CD133+/CD44+/CD117+ basal cell was capable of reconstituting a prostate in the kidney capsule of recipient mice [16]. Garraway et al. demonstrate that a small population of human prostate cells with a basal phenotype and low AR expression is sufficient to induce prostatic gland structures in vivo [17]. Finally, elegant lineagemarking experiments identified a population of AR-negative basal multipotent stem cells with the capacity to differentiate into each of the prostate epithelial lineages (basal, luminal, and neuroendocrine cells) [18]. Thus, it can be concluded that prostate stem cells are most likely AR-negative.

\section{The AR in Prostate Cancer Stem Cells}

There is increasingly awareness that deregulated "stem cells" may be the real culprit for cancer growth, dissemination, and therapy resistance [19-21]. Colloquially referred to as cancer stem cells it is not yet understood if these cells are the progeny of mutated somatic stem cells [22-25] or if they arise de novo from reactivation of stem cell transcriptional networks in more differentiated cell types [26-28]. Irrespective of their origin, parallels can be drawn between somatic stem cells and CSCs. Both types of cells self-renew, although somatic stem cells do so in a highly regulated manner while CSCs are more poorly controlled. Moreover, both types of cells differentiate; somatic stem cells generate normal, mature cells whereas CSCs generate phenotypically diverse nontumorigenic cancer cells [20]. The phenotypic similarity between normal and cancer stem cells raises the possibility that CSCs are "diseased" stem cells and thus targeting stem cell-associated signaling nodes may represent a rational strategy to improve cancer therapy.

3.1. The Origin of Prostate Cancer Stem Cells. It has been suggested that normal stem cells acquire genetic 
and/or epigenetic alterations to transform into CSCs. In particular, the fact that prostate cancer stem cells $(\mathrm{CD} 44+/ \mathrm{CD} 133+/ \alpha 2 \beta 1+)$ share antigenic properties with prostate stem cells $(\mathrm{CD} 133+/ \alpha 2 \beta 1+)$ supports the idea that they arise from the normal stem/progenitor cell counterpart [29-31]. This notion is further exemplified by the fact that CSCs isolated from human prostate tumors express basal markers (such as p63), but not the AR or markers of luminal differentiation [32], mirroring the phenotype of normal prostate stem cells. However, this dogma has recently been challenged by the discovery that differentiated, postmitotic cells have the capacity to ascend the tumor hierarchy and reenter the CSC state. The study of Gupta et al. showed us that breast cancer cell populations can interconvert between phenotypic states [26]. In other words, CSCs can arise de novo from non-stem cells. A similar phenomenon has been described in prostate cancer whereby cells can dedifferentiate to a CSC state under the pressure of stressors, such as chemotherapy or nutrient deprivation [33].

3.2. Prostate Cancer Stem Cells Have Low AR Expression and/or Activity. A series of seminal papers published in 2005 provided the earliest evidence for the existence of CSCs in prostate cancer: first, a population of tumorigenic cells with high expression of the ABCG2 drug efflux pump (termed the side population) was isolated in human prostate cancer LAPC9 xenografts [34]; second, ABCG2 was discovered to mediate the efflux of androgen in putative CSCs [35]; and third, cells isolated from prostate tumors based on the cell surface markers CD $44+/ C D 133+/ \alpha 2 \beta 1+$ could selfrenew and differentiate to generate a phenotypically mixed population [29]. Since then, prostate CSCs have been isolated and purified via expression of cell surface markers, including CD44 [36], CD133, CXCR4 [37], and TRA-1$60 / C D 151 / C D 166$ [38]. Notably, all of the identified subsets of putative prostate CSCs lack AR expression or have low AR activity, which suggests that these cells, like normal prostate stem cells, are inhibited by AR signaling.

Indeed, knockdown of the AR in immortalized epithelial cells results in the expansion of the CSC pool [39], while overexpression of the AR in CD133-positive CSCs reduces their self-renewal capacity [40]. Keeping with these findings, the CSC population is expanded dramatically following androgen deprivation therapy (ADT) both in mouse models and in patient tumors [40-42]. For example, Qin and colleagues discovered a small population of cells defined by low expression of prostate specific antigen (PSA), a transcriptional target of the $\mathrm{AR}$, that resist castration and exhibit heightened self-renewal capacity [43]. These cells are also capable of asymmetric cell division to regenerate a phenotypically mixed tumor, including AR-positive and PSA-positive cells. Notably, the ALDH+/CD $44+/ \alpha 2 \beta 1+$ CSC population can be prospectively purified in PSA-/lo cells indicating that low AR expression and/or activity is a distinguishing feature of CSCs, at least in the prostate.

3.3. Low AR Expression Is a Common Feature of Cancer Stem Cells. Circumstantial evidence suggests that the AR may also play a role in leukemia, breast, and brain CSCs. In leukemia, AR expression is silenced, in part, due to increased methylation of CpG islands in the AR promoter [44]. Similarly, triple-negative breast cancer, which is enriched in CSCs, is generally AR-negative and these tumors are most likely to recur [45]. Finally, glioblastoma stem cells require STAT3 for proliferation and maintenance of multipotency [46], and loss of the AR yields STAT3 activation [47]. Although it appears that the AR may have a far broader role in regulating CSCs than initially imagined, clearly, further studies are required to evaluate AR regulation of CSC phenotype in other cancers outside of prostate cancer.

\section{The AR in Stem Cell Signaling Networks}

Complex regulatory networks are known to maintain cells in distinct cell fates $[48,49]$. These developmental signaling pathways that govern pluripotency and self-renewal in normal stem cells are generally thought to be shared with cancer stem cells $[50,51]$. For example, it was recently demonstrated that prostate tumors with a stem-like phenotype molecularly resemble normal stem cells residing within the human prostate [52]. Although the rewiring of stem cell regulatory networks remains poorly understood, emerging studies suggest that the AR coordinates the activity of stem cell-associated signaling nodes that "tip-the-balance" between a stem cell and differentiated cell state (Figure 1).

4.1. The Core Regulatory Circuitry. The pluripotent state is largely governed by the core transcription factors Oct4, Sox2, and Nanog $[53,54]$. Oct4 and Nanog were first identified based on their relatively unique expression in ESCs and genetic knockout studies showing that they are essential for establishing or maintaining a robust pluripotent state [5557]. Oct 4 functions as a heterodimer with Sox2, thus placing it among the core regulators [58]. Notably, forced expression of Oct 4 and Sox 2 facilitates the reprogramming of somatic cells into induced pluripotent stem (iPS) cells [59]. Although ESCs can be propagated in the absence of Nanog, it cooccupies most sites with Oct 4 and Sox 2 throughout the ESC genome and functions to promote a stable undifferentiated ESC state $[60,61]$.

How might cells integrate signals from their environment and choose whether to remain pluripotent or differentiate into progenitors? The AR has been implicated as a "molecular switch" that functions in coordinately regulating the expression of the pluripotency transcription factors: Sox2, Oct4, and Nanog. In ESCs and prostate epithelial cells increased AR signaling decreases Sox2 expression. This is the result of AR binding to the enhancer element within the Sox 2 promoter where it acts as a transcriptional repressor [62]. The AR also binds directly to the Nanog promoter [63], and in cell lines and patient specimens Nanog and the AR are reciprocally expressed $[64,65]$. Finally, while no studies have directly addressed the role of the $\mathrm{AR}$ in the regulation of Oct4, it has been reported that Oct4 is increased during neuroendocrine differentiation $[66,67]$ and neuroendocrine cells are largely AR-negative [68]. Taken together, these 


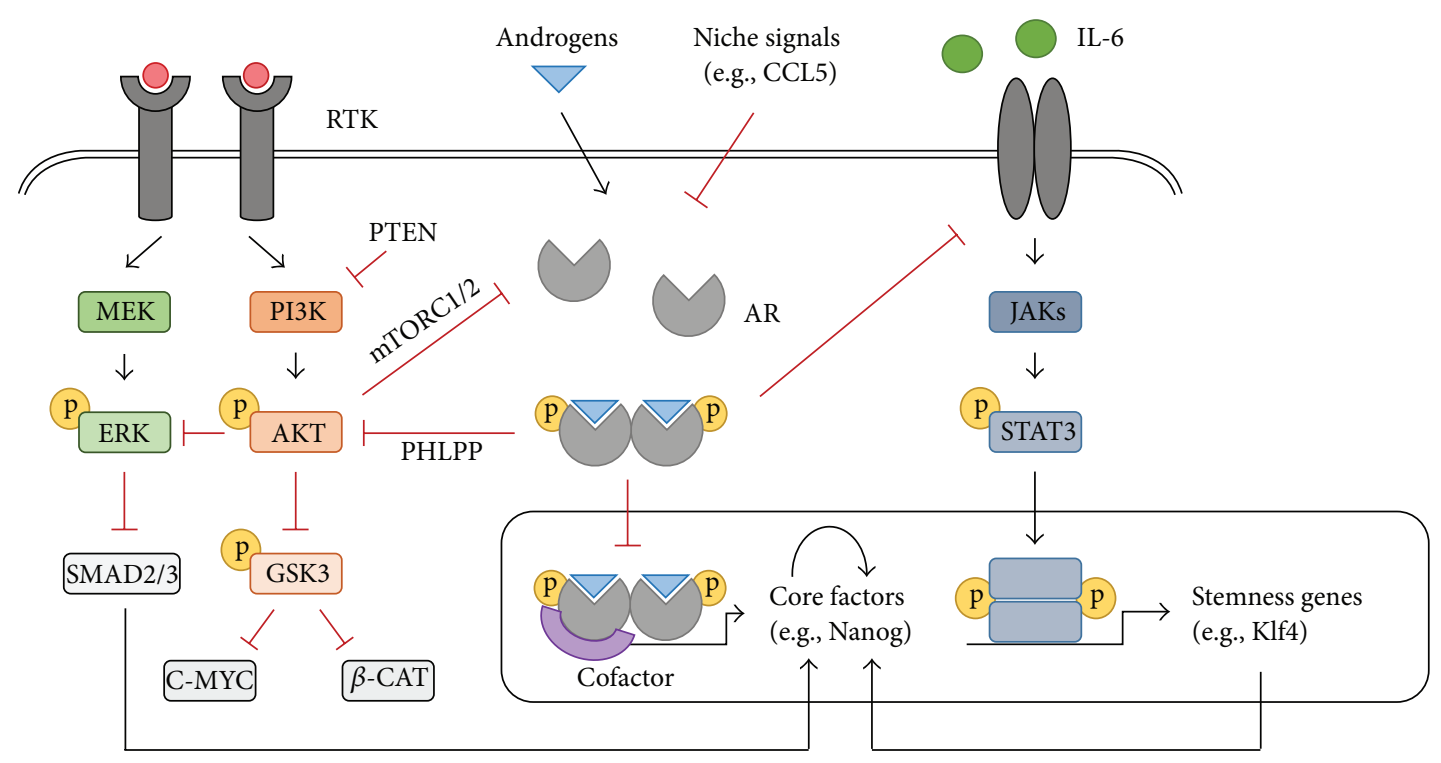

FIGURE 1: Regulation of interconnected stem cell signaling nodes by the AR. Activation of the AR negatively regulates the core pluripotency transcription factors (Nanog, Sox2, and Oct4) as well as signaling cascades that reinforce a robust stem cell state. The AR (1) acts as a transcriptional repressor at the Nanog and Sox2 promoters; (2) inhibits PI3K/Akt signaling through induction of PHLPP, which dephosphorylates Akt to facilitate ERK pathway activation leading to Nanog gene repression, as well as GSK3-mediated c-myc and $\beta$-catenin repression; and (3) blocks STAT3-mediated transcription of stem cell-associated genes by inhibiting IL-6. Suppression of the AR by factors in the stem cell niche, such as CCL5, relieves this inhibition to favor self-renewal and pluripotency over differentiation. AR, androgen receptor; $\beta$ CAT, $\beta$-catenin; CCL5, chemokine ligand 5; IL-6, interleukin-6; JAK, Janus kinase; PHLPP, PH domain and leucine rich protein phosphatase; RTK, receptor tyrosine kinase.

studies suggest that the AR functions upstream of Sox2, Oct4, and Nanog to orchestrate their coordinated regulation during cell fate transitions.

4.2. PI3K/Akt Signaling: Cross-Talk with Myc and ERK. Phosphoinositide-3 kinase (PI3K)/Akt has been implicated in regulating stem cell transcriptional networks given the discovery that ESCs lacking Pten, which encodes a phosphatase that antagonizes PI3K signaling, exhibit enhanced proliferation and form teratomas composed of undifferentiated cells in vivo [69]. Similarly, the deletion of Pten during haematopoiesis was found to increase the HSC pool [70]. These findings have been corroborated by studies in human ESC cultures where inhibition of PI3K using the small molecule inhibitor LY294002 or removal of PI3K activators contributes to loss of pluripotency and triggers differentiation [71-73]. Like normal stem cells, the proliferation as well as maintenance of CSCs is also dependent on PI3K/Akt signaling. Pten knockdown in DU145 prostate cancer cells yields an enrichment in CD133+/CD44+ CSCs, while treatment with LY294002 reduces sphere formation [74].

Recent studies indicate that androgen depletion or knockdown of AR expression results in elevated levels of activated Akt $[75,76]$, suggesting that $A R$ negatively regulates PI3K/Akt signaling. Akt phosphorylates numerous target proteins, notably, GSK3 leading to its degradation. One effect of GSK 3 inhibition in this context is to stabilize $\beta$-catenin, a transcriptional coactivator implicated in stem cell regulation [77]. In particular, it has been proposed that the AR inhibits the self-renewal of ESCs and BM-MSCs through suppression of Akt signaling $[9,78]$. This is, at least in part, mediated via the AKT/GSK3/ $\beta$-catenin signaling pathway as knockdown of $\beta$-catenin prevents BM-MSC differentiation in response to androgens [79].

AKT-mediated GSK3 inhibition also functions to stabilize c-myc [80], a key regulator in the maintenance of pluripotency and self-renewal. Interest in Myc function in stem cells was ignited by studies linking both c-myc and $\mathrm{N}$ myc to the generation of iPS cells $[59,81]$, the regulation of self-renewal in ESCs $[80,82]$, and tumor stem cell maintenance [83]. Knockout of Myc in ESC lines yields a profound disruption in pluripotency and self-renewal, while inducing differentiation into ectoderm, mesoderm, and endoderm derivatives [84]. Genomic studies have suggested that c-myc targets are involved predominately in cellular metabolism, cell cycle, and protein synthesis pathways. In particular, Myccentered transcriptional network composed of over 500 genes is upregulated in ESCs, iPS cells, and poorly differentiated, stem-like tumors emphasizing the pervasive nature of the Myc regulatory network in maintaining the stem cell state [85].

Apart from Myc, a second downstream target of the PI3K/Akt signaling cascade that supports a stem cell state is the core pluripotency factor Nanog. Nanog expression is downregulated following $\mathrm{PI} 3 \mathrm{~K}$ inhibition [86, 87] and this can be attributed to cross-talk between the PI3K/Akt and ERK signaling pathways. In particular, PI3K/Akt suppresses ERK signaling, which has a well-established role in antagonizing pluripotency in ESCs $[88,89]$. This likely involves ERK-mediated phosphorylation of Smad proteins 
resulting in decreased activity and nuclear translocation [90]. Thus, under self-renewing conditions, the absence of ERK signaling permits Smad2/3 to transcriptionally activate Nanog in addition to other pluripotency-associated genes $[73,91]$. A second feedback loop between the AR and ERK further dampens ERK activity in cells with low AR expression [92]. Together, these studies raise the possibility that negative regulation of PI3K/Akt by the AR potentiates Myc and/or Nanog expression to maintain pluripotency and self-renewal.

4.3. STAT3 Signaling Reinforces the Stem Cell State. A role for Signal Transducer and Activator of Transcription 3 (STAT3) in sustaining pluripotency and self-renewal capacity has been described in ESCs $[93,94]$ as well as CSCs, notably glioblastoma stem cells [46], breast cancer stem cells [95], and prostate cancer stem cells [47]. For instance, increasing STAT3 activity is sufficient to reprogram primed pluripotent stem cells back to naive-like ESCs [96], while expressing a dominate negative STAT3 mutant in ESCs abrogates selfrenewal and promotes differentiation [94]. Likewise, treatment of DU145 prostate cancer cells with the STAT3 inhibitor galiellalactone reduces the frequency of ALDH-positive CSCs [97].

The STAT3 transcription factor is activated by the binding of inflammatory cytokines or growth factors in the interleukin- (IL-) 6 and IL-10 family to their cognate receptors on the cell surface. This potentiates intracellular signal transduction cascades in which receptor-associated Janus kinases (JAKs) phosphorylate STAT3 leading to its dimerization and nuclear translocation [98]. In particular, STAT3-mediated upregulation of Klf4 and/or Tfcp2L1 is sufficient to revert cells back to a pluripotent ESC-like state $[99,100]$. A global analysis of promotor occupancy revealed Klf4 directly regulates a large, feed-forward loop that contains the core pluripotency factors and also occupies the c-myc promoter to potentiate a stem cell state [101]. The key role for STAT3 in maintaining pluripotency and self-renewal is supported by the observations that JAK/STAT3 signaling is a limiting factor in the reprogramming of somatic cells to naïve pluripotency [102], and that JAK/STAT3 signaling can be dominant over antagonistic FGF/ERK signaling to reinforce a pluripotent state [103].

Recent evidence suggests that STAT3 is negatively regulated by the AR. In prostate cancer cell lines downregulation of the AR increases STAT3 signaling, which is required for CSC maintenance. Moreover, in human prostate tumor tissue, cells with low AR expression exhibit high STAT3 activity and coexpress CSC markers, including Nanog and CD44 [47]. It has been proposed that AR downregulation increases IL-6 expression and, in turn, STAT3 activation. Notably, IL6 has been implicated in the generation of iPS cells via activation of the JAK/STAT target Pim1 [104]. Inhibition of JAK/STAT3 signaling by gene silencing or using an IL-6 receptor fusion protein (IL- $6^{\mathrm{RFP}}$ ), which acts as a cytokine trap to sequester soluble IL-6, exhausts the CSC population in both murine and human prostate cancer models [47]. This is consistent with studies in glioblastoma showing that inhibition of IL-6 or its receptor, IL-6R $\alpha$, diminishes STAT3 activation and, in turn, the number of glioblastoma stem cells [105].

4.4. Transcriptional Cofactors Reprogram the AR. The AR does not function in isolation, but rather associates with cofactors that can alter its function. In this way the AR can be "reprogrammed." Of particular interest is enhancer of zeste homologue 2 (EZH2), an epigenetic regulator with a welldocumented role in regulating cell fate [106]. A pioneering study by $\mathrm{Xu}$ and colleagues demonstrated that in androgenindependent prostate cancer EZH2 interacts with the AR, which alters the AR cistrome (genomic binding sites) to activate a unique transcriptional program [107]. While this study did not address EZH2 and AR interaction within the CSC population per se, it is tempting to speculate that noncanonical AR signaling may be involved in regulating the stem cell state.

\section{AR Regulation by the Stem Cell Niche}

The stem cell niche provides a microenvironment that is capable of protecting and perpetuating the self-renewing, undifferentiated state of stem cells. It is composed not only of stem cells but also of a rich array of neighbouring differentiated cell types which secrete a rich milieu of extracellular matrix and other soluble factors that allow stem cells to manifest their unique intrinsic properties [108].

It has been recently emerged that BM-MSCs recruited to tumors secrete the chemokine CCL5 (also called RANTES), which acts in a paracrine fashion to suppress AR signaling in neighbouring cancer cells [109]. This results in an increased CSC population, suggesting that BM-MSCs regulate the stem cell phenotype by secreting CCL5 $[109,110]$. This phenotype is reversible and is dependent on CCL5-mediated upregulation of hypoxia inducible factor $2 \alpha$ (HIF $2 \alpha$ ), which alters AR:HSP90 interaction to suppress AR transactivation [111].

Similarly, endothelial cells secrete IL-6 to suppress the AR signaling axis [112]. This coincides with expansion of the stem cell pool, and treating mice with soluble IL-6 receptor fusion protein reduces the CSC population in prostate cancer [47]. Notably, endothelial cells have been reported to provide a niche for HSC expansion [113], supporting the notion that these cells promote the maintenance of stem cells that reside in close contact.

One final note is that cross-talk between non-stem and stem cell niches is not likely to be unidirectional. In fact, transcriptional profiling of stem cells reveals that they synthesize a number of growth factors that appear tailored for their neighbouring niche cells [114]. For example, in transwell assays BM-MSCs migrate avidly towards media derived from breast cancer cell lines [115]. Although the cellular communication pathways remain poorly defined, understanding how the stem cell niche is constructed will be a rich area for future studies.

\section{Conclusions and Outlook}

How do regulators of the stem cell gene expression program produce a self-renewing cell that remains poised for 
differentiation? Part of the answer is that the AR functions as a finely balanced "molecular switch," integrating extrinsic signals to control the core pluripotency transcription factors as well as key signaling pathways that reinforce the stem cell state, such as PI3K/Akt and STAT3. In its "off" state the AR supports a transcriptional program that favors self-renewal, yet once activated the AR rewires the transcriptional circuitry to drive differentiation.

Overall, the AR pathway functions at critical crossroads in balancing stem cell self-renewal versus differentiation. Indeed, the importance of the AR in regulating stem cell plasticity is evident by its conserved role across embryonic and somatic stem cells, in addition to cancer stem cells. Future avenues of research will continue to advance our knowledge and understanding of the AR function in stem cells. These include, but are not limited to, determining how the AR directs differentiation along a specific lineage, ascertaining the role of AR cofactors, and understanding the influence of specific stem cell niches on AR expression. Such studies will lead to optimizations in stem cell-based therapy as well as new drug targets in CSCs to improve cancer outcomes.

\section{Conflict of Interests}

The authors declare that there is no conflict of interests regarding the publication of this paper.

\section{Acknowledgments}

This work was supported by Prostate Cancer Canada and the Movember Foundation (Grant T2013-01), with additional support from the Canadian Institutes of Health Research (to Alastair H. Davies).

\section{References}

[1] R. Jaenisch and R. Young, "Stem cells, the molecular circuitry of pluripotency and nuclear reprogramming," Cell, vol. 132, no. 4, pp. 567-582, 2008.

[2] M. E. Tan, J. Li, H. E. Xu, K. Melcher, and E.-L. Yong, "Androgen receptor: structure, role in prostate cancer and drug discovery," Acta Pharmacologica Sinica, vol. 36, no. 1, pp. 3-23, 2015.

[3] S. Yeh, M.-Y. Tsai, Q. Xu et al., "Generation and characterization of androgen receptor knockout (ARKO) mice: an in vivo model for the study of androgen functions in selective tissues," Proceedings of the National Academy of Sciences of the United States of America, vol. 99, no. 21, pp. 13498-13503, 2002.

[4] C. Huggins, "Endocrine-induced regression of cancers," Science, vol. 156, no. 3778, pp. 1050-1054, 1967.

[5] M. Thomson, S. J. Liu, L.-N. Zou, Z. Smith, A. Meissner, and S. Ramanathan, "Pluripotency factors in embryonic stem cells regulate differentiation into germ layers," Cell, vol. 145, no. 6, pp. 875-889, 2011.

[6] C. N. Sauter, R. L. McDermid, A. L. Weinberg et al., "Differentiation of murine embryonic stem cells induces progesterone receptor gene expression," Experimental Cell Research, vol. 311, no. 2, pp. 251-264, 2005.

[7] D. R. Goldman-Johnson, D. M. de Kretser, and J. R. Morrison, "Evidence that androgens regulate early developmental events, prior to sexual differentiation," Endocrinology, vol. 149, no. 1, pp. 5-14, 2008.

[8] A. S. Al Madhoun, A. Voronova, T. Ryan et al., "Testosterone enhances cardiomyogenesis in stem cells and recruits the androgen receptor to the MEF2C and $\mathrm{HCN} 4$ genes," Journal of Molecular and Cellular Cardiology, vol. 60, no. 1, pp. 164-171, 2013.

[9] C.-Y. Chang, Y.-D. Hsuuw, F.-J. Huang et al., "Androgenic and antiandrogenic effects and expression of androgen receptor in mouse embryonic stem cells," Fertility and Sterility, vol. 85, supplement 1, pp. 1195-1203, 2006.

[10] H. F. English, R. J. Santen, and J. T. Isaacs, "Response of glandular versus basal rat ventral prostatic epithelial cells to androgen withdrawal and replacement," The Prostate, vol. 11, no. 3, pp. 229-242, 1987.

[11] A. Tsujimura, Y. Koikawa, S. Salm et al., "Proximal location of mouse prostate epithelial stem cells: a model of prostatic homeostasis," The Journal of Cell Biology, vol. 157, no. 7, pp. 12571265, 2002.

[12] E. J. Robinson, D. E. Neal, and A. T. Collins, "Basal cells are progenitors of luminal cells in primary cultures of differentiating human prostatic epithelium," The Prostate, vol. 37, no. 3, pp. 149$160,1998$.

[13] S. Signoretti and M. Loda, "Defining cell lineages in the prostate epithelium," Cell Cycle, vol. 5, no. 2, pp. 138-141, 2006.

[14] X. Wang, M. K.-D. Julio, K. D. Economides et al., "A luminal epithelial stem cell that is a cell of origin for prostate cancer," Nature, vol. 461, no. 7263, pp. 495-500, 2009.

[15] D. A. Lawson, L. Xin, R. U. Lukacs, D. Cheng, and O. N. Witte, "Isolation and functional characterization of murine prostate stem cells," Proceedings of the National Academy of Sciences of the United States of America, vol. 104, no. 1, pp. 181-186, 2007.

[16] K. G. Leong, B.-E. Wang, L. Johnson, and W.-Q. Gao, "Generation of a prostate from a single adult stem cell," Nature, vol. 456, no. 7223, pp. 804-810, 2008.

[17] I. P. Garraway, W. Sun, C. P. Tran et al., "Human prostate sphereforming cells represent a subset of basal epithelial cells capable of glandular regeneration in vivo," The Prostate, vol. 70, no. 5, pp. 491-501, 2010.

[18] M. Ousset, A. Van Keymeulen, G. Bouvencourt et al., "Multipotent and unipotent progenitors contribute to prostate postnatal development," Nature Cell Biology, vol. 14, no. 11, pp. 1131-1138, 2012.

[19] M. F. Clarke, J. E. Dick, P. B. Dirks et al., "Cancer stem cellsperspectives on current status and future directions: AACR workshop on cancer stem cells," Cancer Research, vol. 66, no. 19, pp. 9339-9344, 2006.

[20] T. Reya, S. J. Morrison, M. F. Clarke, and I. L. Weissman, "Stem cells, cancer, and cancer stem cells," Nature, vol. 414, no. 6859, pp. 105-111, 2001.

[21] H. Clevers, "The cancer stem cell: premises, promises and challenges," Nature Medicine, vol. 17, no. 3, pp. 313-319, 2011.

[22] D. Bonnet and J. E. Dick, "Human acute myeloid leukemia is organized as a hierarchy that originates from a primitive hematopoietic cell," Nature Medicine, vol. 3, no. 7, pp. 730-737, 1997.

[23] K. J. Hope, L. Jin, and J. E. Dick, "Acute myeloid leukemia originates from a hierarchy of leukemic stem cell classes that differ in self-renewal capacity," Nature Immunology, vol. 5, no. 7, pp. 738-743, 2004. 
[24] M. Pérez-Caro, C. Cobaleda, I. González-Herrero et al., "Cancer induction by restriction of oncogene expression to the stem cell compartment," The EMBO Journal, vol. 28, no. 1, pp. 8-20, 2009.

[25] N. Barker, R. A. Ridgway, J. H. van Es et al., "Crypt stem cells as the cells-of-origin of intestinal cancer," Nature, vol. 457, no. 7229, pp. 608-611, 2009.

[26] P. B. Gupta, C. M. Fillmore, G. Jiang et al., "Stochastic state transitions give rise to phenotypic equilibrium in populations of cancer cells," Cell, vol. 146, pp. 633-644, 2011.

[27] C. L. Chaffer, I. Brueckmann, C. Scheel et al., "Normal and neoplastic nonstem cells can spontaneously convert to a stemlike state," Proceedings of the National Academy of Sciences of the United States of America, vol. 108, no. 19, pp. 7950-7955, 2011.

[28] W. A. Flavahan, Q. Wu, M. Hitomi et al., "Brain tumor initiating cells adapt to restricted nutrition through preferential glucose uptake," Nature Neuroscience, vol. 16, no. 10, pp. 1373-1382, 2013.

[29] A. T. Collins, P. A. Berry, C. Hyde, M. J. Stower, and N. J. Maitland, "Prospective identification of tumorigenic prostate cancer stem cells," Cancer Research, vol. 65, no. 23, pp. 1094610951, 2005.

[30] A. T. Collins, F. K. Habib, N. J. Maitland, and D. E. Neal, "Identification and isolation of human prostate epithelial stem cells based on $\alpha_{2} \beta_{1}$-integrin expression," Journal of Cell Science, vol. 114, no. 21, pp. 3865-3872, 2001.

[31] G. D. Richardson, C. N. Robson, S. H. Lang, D. E. Neal, N. J. Maitland, and A. T. Collins, "CD133, a novel marker for human prostatic epithelial stem cells," Journal of Cell Science, vol. 117, no. 16, pp. 3539-3545, 2004.

[32] N. J. Maitland, F. M. Frame, E. S. Polson, J. L. Lewis, and A. T. Collins, "Prostate cancer stem cells: do they have a basal or luminal phenotype?" Hormones \& Cancer, vol. 2, no. 1, pp. 4761, 2011.

[33] Y. Tang, A. W. Hamburger, L. Wang, M. A. Khan, and A. Hussain, "Androgen deprivation and stem cell markers in prostate cancers," International Journal of Clinical and Experimental Pathology, vol. 3, no. 2, pp. 128-138, 2009.

[34] L. Patrawala, T. Calhoun, R. Schneider-Broussard, J. Zhou, K. Claypool, and D. G. Tang, "Side population is enriched in tumorigenic, stem-like cancer cells, whereas $\mathrm{ABCG}^{+}$ and $\mathrm{ABCG}^{-}$cancer cells are similarly tumorigenic," Cancer Research, vol. 65, no. 14, pp. 6207-6219, 2005.

[35] W. J. Huss, D. R. Gray, N. M. Greenberg, J. L. Mohler, and G. J. Smith, "Breast cancer resistance protein-mediated efflux of androgen in putative benign and malignant prostate stem cells," Cancer Research, vol. 65, no. 15, pp. 6640-6650, 2005.

[36] L. Patrawala, T. Calhoun, R. Schneider-Broussard et al., "Highly purified CD44+ prostate cancer cells from xenograft human tumors are enriched in tumorigenic and metastatic progenitor cells," Oncogene, vol. 25, no. 12, pp. 1696-1708, 2006.

[37] J. Miki, B. Furusato, H. Li et al., "Identification of putative stem cell markers, CD133 and CXCR4, in hTERT-immortalized primary nonmalignant and malignant tumor-derived human prostate epithelial cell lines and in prostate cancer specimens," Cancer Research, vol. 67, no. 7, pp. 3153-3161, 2007.

[38] V. K. Rajasekhar, L. Studer, W. Gerald, N. D. Socci, and H. I. Scher, "Tumour-initiating stem-like cells in human prostate cancer exhibit increased NF- $\kappa$ B signalling," Nature Communications, vol. 2, article 162, 2011.

[39] Y. Niu, S. Altuwaijri, S. Yeh et al., "Targeting the stromal androgen receptor in primary prostate tumors at earlier stages," Proceedings of the National Academy of Sciences of the United States of America, vol. 105, no. 34, pp. 12188-12193, 2008.
[40] S. O. Lee, Z. Ma, C.-R. Yeh et al., "New therapy targeting differential androgen receptor signaling in prostate cancer stem/progenitor vs. non-stem/progenitor cells," Journal of Molecular Cell Biology, vol. 5, no. 1, pp. 14-26, 2013.

[41] M. Germann, A. Wetterwald, N. Guzmán-Ramirez et al., "Stemlike cells with luminal progenitor phenotype survive castration in human prostate cancer," STEM CELLS, vol. 30, no. 6, pp. 1076-1086, 2012.

[42] D. Seiler, J. Zheng, G. Liu et al., "Enrichment of putative prostate cancer stem cells after androgen deprivation: upregulation of pluripotency transactivators concurs with resistance to androgen deprivation in LNCaP cell lines," Prostate, vol. 73, no. 13, pp. 1378-1390, 2013.

[43] J. Qin, X. Liu, B. Laffin et al., "The PSA ${ }^{-/ l o}$ prostate cancer cell population harbors self-renewing long-term tumorpropagating cells that resist castration," Cell Stem Cell, vol. 10, pp. 556-569, 2012.

[44] Z.-J. Liu, G. Wang, Y. Cai et al., "Androgen receptor CpG island methylation status in human leukemia cancer cells," Cancer Investigation, vol. 27, no. 2, pp. 156-162, 2009.

[45] A. A. Thike, L. Y.-Z. Chong, P. Y. Cheok et al., "Loss of androgen receptor expression predicts early recurrence in triple-negative and basal-like breast cancer," Modern Pathology, vol. 27, no. 3, pp. 352-360, 2014.

[46] M. M. Sherry, A. Reeves, J. K. Wu, and B. H. Cochran, "STAT3 is required for proliferation and maintenance of multipotency in glioblastoma stem cells," STEM CELLS, vol. 27, no. 10, pp. 23832392, 2009

[47] A. Schroeder, A. Herrmann, G. Cherryholmes et al., "Loss of androgen receptor expression promotes a stem-like cell phenotype in prostate cancer through STAT3 signaling," Cancer Research, vol. 74, no. 4, pp. 1227-1237, 2014.

[48] E. H. Davidson, J. P. Rast, P. Oliveri et al., "A genomic regulatory network for development," Science, vol. 295, no. 5560, pp. 1669$1678,2002$.

[49] N. Novershtern, A. Subramanian, L. N. Lawton et al., "Densely interconnected transcriptional circuits control cell states in human hematopoiesis," Cell, vol. 144, no. 2, pp. 296-309, 2011.

[50] I. Ben-Porath, M. W. Thomson, V. J. Carey et al., "An embryonic stem cell-like gene expression signature in poorly differentiated aggressive human tumors," Nature Genetics, vol. 40, no. 5, pp. 499-507, 2008

[51] D. J. Wong, H. Liu, T. W. Ridky, D. Cassarino, E. Segal, and H. Y. Chang, "Module map of stem cell genes guides creation of epithelial cancer stem cells," Cell Stem Cell, vol. 2, no. 4, pp. 333344, 2008.

[52] B. A. Smith, A. Sokolov, V. Uzunangelov et al., "A basal stem cell signature identifies aggressive prostate cancer phenotypes," Proceedings of the National Academy of Sciences of the United States of America, vol. 112, no. 47, pp. E6544-E6552, 2015.

[53] I. Chambers and A. Smith, "Self-renewal of teratocarcinoma and embryonic stem cells," Oncogene, vol. 23, no. 43, pp. 71507160,2004

[54] H. Niwa, "How is pluripotency determined and maintained?" Development, vol. 134, no. 4, pp. 635-646, 2007.

[55] I. Chambers, D. Colby, M. Robertson et al., "Functional expression cloning of Nanog, a pluripotency sustaining factor in embryonic stem cells," Cell, vol. 113, no. 5, pp. 643-655, 2003.

[56] K. Mitsui, Y. Tokuzawa, H. Itoh et al., “The homeoprotein nanog is required for maintenance of pluripotency in mouse epiblast and ES cells," Cell, vol. 113, no. 5, pp. 631-642, 2003. 
[57] H. Niwa, J.-I. Miyazaki, and A. G. Smith, "Quantitative expression of Oct-3/4 defines differentiation, dedifferentiation or selfrenewal of ES cells," Nature Genetics, vol. 24, no. 4, pp. 372-376, 2000.

[58] S. Masui, Y. Nakatake, Y. Toyooka et al., "Pluripotency governed by Sox 2 via regulation of Oct $3 / 4$ expression in mouse embryonic stem cells," Nature Cell Biology, vol. 9, no. 6, pp. 625-635, 2007.

[59] K. Takahashi and S. Yamanaka, "Induction of pluripotent stem cells from mouse embryonic and adult fibroblast cultures by defined factors," Cell, vol. 126, no. 4, pp. 663-676, 2006.

[60] A. Marson, S. S. Levine, M. F. Cole et al., "Connecting microRNA genes to the core transcriptional regulatory circuitry of embryonic stem cells," Cell, vol. 134, no. 3, pp. 521-533, 2008.

[61] I. Chambers, J. Silva, D. Colby et al., "Nanog safeguards pluripotency and mediates germline development," Nature, vol. 450, no. 7173, pp. 1230-1234, 2007.

[62] S. Kregel, K. J. Kiriluk, A. M. Rosen et al., "Sox2 is an androgen receptor-repressed gene that promotes castrationresistant prostate cancer," PLOS ONE, vol. 8, no. 1, Article ID e53701, 2013.

[63] S. Kregel, R. Z. Szmulewitz, and D. J. V. Griend, “The pluripotency factor Nanog is directly upregulated by the androgen receptor in prostate cancer cells," The Prostate, vol. 74, pp. 15301543, 2014.

[64] C. R. Jeter, M. Badeaux, G. Choy et al., "Functional evidence that the self-renewal gene NANOG regulates human tumor development," STEM CELLS, vol. 27, no. 5, pp. 993-1005, 2009.

[65] C. R. Jeter, B. Liu, X. Liu et al., "NANOG promotes cancer stem cell characteristics and prostate cancer resistance to androgen deprivation,” Oncogene, vol. 30, no. 36, pp. 3833-3845, 2011.

[66] P. Sotomayor, A. Godoy, G. J. Smith, and W. J. Huss, "Oct4A is expressed by a subpopulation of prostate neuroendocrine cells," The Prostate, vol. 69, no. 4, pp. 401-410, 2009.

[67] N. Monsef, M. Soller, M. Isaksson, P. A. Abrahamsson, and I. Panagopoulos, "The expression of pluripotency marker oct $3 / 4$ in prostate cancer and benign prostate hyperplasia," Prostate, vol. 69, no. 9, pp. 909-916, 2009.

[68] H. Bonkhoff, "Neuroendocrine cells in benign and malignant prostate tissue: morphogenesis, proliferation, and androgen receptor status," The Prostate, Supplement, vol. 8, pp. 18-22, 1998.

[69] H. Sun, R. Lesche, D.-M. Li et al., "PTEN modulates cell cycle progression and cell survival by regulating phosphatidylinositol 3,4,5,-trisphosphate and Akt/protein kinase B signaling pathway," Proceedings of the National Academy of Sciences of the United States of America, vol. 96, no. 11, pp. 6199-6204, 1999.

[70] J. Zhang, J. C. Grindley, T. Yin et al., "PTEN maintains haematopoietic stem cells and acts in lineage choice and leukaemia prevention," Nature, vol. 441, no. 7092, pp. 518-522, 2006.

[71] A. B. McLean, K. A. D’Amour, K. L. Jones et al., "Activin A efficiently specifies definitive endoderm from human embryonic stem cells only when phosphatidylinositol 3-kinase signaling is suppressed," Stem Cells, vol. 25, no. 1, pp. 29-38, 2007.

[72] S. C. Bendall, M. H. Stewart, P. Menendez et al., "IGF and FGF cooperatively establish the regulatory stem cell niche of pluripotent human cells in vitro," Nature, vol. 448, no. 7157, pp. 1015-1021, 2007.

[73] A. M. Singh, D. Reynolds, T. Cliff et al., "Signaling network crosstalk in human pluripotent cells: a Smad2/3-regulated switch that controls the balance between self-renewal and differentiation," Cell Stem Cell, vol. 10, no. 3, pp. 312-326, 2012.
[74] A. Dubrovska, S. Kim, R. J. Salamone et al., "The role of PTEN/Akt/PI3K signaling in the maintenance and viability of prostate cancer stem-like cell populations," Proceedings of the National Academy of Sciences of the United States of America, vol. 106, no. 1, pp. 268-273, 2009.

[75] S. H. Lee, D. Johnson, R. Luong, and Z. Sun, "Crosstalking between androgen and PI3K/AKT signaling pathways in prostate cancer cells," The Journal of Biological Chemistry, vol. 290, no. 5, pp. 2759-2768, 2015.

[76] B. S. Carver, C. Chapinski, J. Wongvipat et al., "Reciprocal feedback regulation of PI3K and androgen receptor signaling in PTEN-deficient prostate cancer," Cancer Cell, vol. 19, no. 5, pp. 575-586, 2011.

[77] N. Sato, L. Meijer, L. Skaltsounis, P. Greengard, and A. H. Brivanlou, "Maintenance of pluripotency in human and mouse embryonic stem cells through activation of Wnt signaling by a pharmacological GSK-3-specific inhibitor," Nature Medicine, vol. 10, no. 1, pp. 55-63, 2004.

[78] C.-K. Huang, M.-Y. Tsai, J. Luo, H.-Y. Kang, S. O. Lee, and C. Chang, "Suppression of androgen receptor enhances the selfrenewal of mesenchymal stem cells through elevated expression of EGFR," Biochimica et Biophysica Acta, vol. 1833, no. 5, pp. 1222-1234, 2013.

[79] R. Singh, S. Bhasin, M. Braga et al., "Regulation of myogenic differentiation by androgens: cross talk between androgen receptor $\beta$-catenin and follistatin/transforming growth factor$\beta$ signaling pathways," Endocrinology, vol. 150, no. 3, pp. 1259$1268,2009$.

[80] M. Bechard and S. Dalton, "Subcellular localization of glycogen synthase kinase 3beta controls embryonic stem cell selfrenewal," Molecular and Cellular Biology, vol. 29, no. 8, pp. 2092-2104, 2009.

[81] R. Sridharan, J. Tchieu, M. J. Mason et al., "Role of the murine reprogramming factors in the induction of pluripotency," Cell, vol. 136, no. 2, pp. 364-377, 2009.

[82] P. Cartwright, C. McLean, A. Sheppard, D. Rivett, K. Jones, and S. Dalton, "LIF/STAT3 controls ES cell self-renewal and pluripotency by a Myc-dependent mechanism," Development, vol. 132, no. 5, pp. 885-896, 2005.

[83] J. Wang, H. Wang, Z. Li et al., "c-Myc is required for maintenance of glioma cancer stem cells," PLoS ONE, vol. 3, no. 11, Article ID e3769, 2008.

[84] N. V. Varlakhanova, R. F. Cotterman, W. N. deVries et al., " $m y c$ maintains embryonic stem cell pluripotency and self-renewal," Differentiation, vol. 80, no. 1, pp. 9-19, 2010.

[85] J. Kim, A. J. Woo, J. Chu et al., "A Myc network accounts for similarities between embryonic stem and cancer cell transcription programs," Cell, vol. 143, no. 2, pp. 313-324, 2010.

[86] M. P. Storm, H. K. Bone, C. G. Beck et al., "Regulation of nanog expression by phosphoinositide 3-kinase-dependent signaling in murine embryonic stem cells," The Journal of Biological Chemistry, vol. 282, no. 9, pp. 6265-6273, 2007.

[87] K. Takahashi, M. Murakami, and S. Yamanaka, "Role of the phosphoinositide 3-kinase pathway in mouse embryonic stem (ES) cells," Biochemical Society Transactions, vol. 33, no. 6, pp. 1522-1525, 2005.

[88] J. Na, M. K. Furue, and P. W. Andrews, "Inhibition of ERK1/2 prevents neural and mesendodermal differentiation and promotes human embryonic stem cell self-renewal," Stem Cell Research, vol. 5, no. 2, pp. 157-169, 2010. 
[89] W. B. Hamilton and J. M. Brickman, "Erk signaling suppresses embryonic stem cell self-renewal to specify endoderm," Cell Reports, vol. 9, no. 6, pp. 2056-2070, 2014.

[90] M. Kretzschmar, J. Doody, and J. Massagué, “Opposing BMP and EGF signalling pathways converge on the TGF- $\beta$ family mediator Smad1," Nature, vol. 389, no. 6651, pp. 618-622, 1997.

[91] R.-H. Xu, T. L. Sampsell-Barron, F. Gu et al., "NANOG is a direct target of TGFbeta/activin-mediated SMAD signaling in human ESCs," Cell Stem Cell, vol. 3, no. 2, pp. 196-206, 2008.

[92] K. M. Chia, J. Liu, G. D. Francis, and A. Naderi, "A feedback loop between androgen receptor and ERK signaling in estrogen receptor-negative breast cancer," Neoplasia, vol. 13, no. 2, pp. 154-166, 2011.

[93] R. Raz, C.-K. Lee, L. A. Cannizzaro, P. D’Eustachio, and D. E. Levy, "Essential role of STAT3 for embryonic stem cell pluripotency," Proceedings of the National Academy of Sciences of the United States of America, vol. 96, no. 6, pp. 2846-2851, 1999.

[94] H. Niwa, T. Burdon, I. Chambers, and A. Smith, "Self-renewal of pluripotent embryonic stem cells is mediated via activation of STAT3," Genes and Development, vol. 12, no. 13, pp. 2048-2060, 1998.

[95] L. L. C. Marotta, V. Almendro, A. Marusyk et al., "The JAK2/STAT3 signaling pathway is required for growth of $\mathrm{CD} 44^{+} \mathrm{CD} 24^{-}$stem cell-like breast cancer cells in human tumors," The Journal of Clinical Investigation, vol. 121, no. 7, pp. 2723-2735, 2011.

[96] H. Chen, I. Aksoy, F. Gonnot et al., "Reinforcement of STAT3 activity reprogrammes human embryonic stem cells to naivelike pluripotency," Nature Communications, vol. 6, article 7095, 2015.

[97] R. Hellsten, M. Johansson, A. Dahlman, N. Dizeyi, O. Sterner, and A. Bjartell, "Galiellalactone is a novel therapeutic candidate against hormone-refractory prostate cancer expressing activated Stat3," The Prostate, vol. 68, no. 3, pp. 269-280, 2008.

[98] J. E. Darnell Jr., I. M. Kerr, and G. R. Stark, "Jak-STAT pathways and transcriptional activation in response to IFNs and other extracellular signaling proteins," Science, vol. 264, no. 5164, pp. 1415-1421, 1994.

[99] G. Martello, P. Bertone, and A. Smith, "Identification of the missing pluripotency mediator downstream of leukaemia inhibitory factor," The EMBO Journal, vol. 32, no. 19, pp. 25612574, 2013.

[100] G. Guo, J. Yang, J. Nichols et al., "Klf4 reverts developmentally programmed restriction of ground state pluripotency," Development, vol. 136, no. 7, pp. 1063-1069, 2009.

[101] J. Kim, J. Chu, X. Shen, J. Wang, and S. H. Orkin, "An extended transcriptional network for pluripotency of embryonic stem cells," Cell, vol. 132, no. 6, pp. 1049-1061, 2008.

[102] J. Yang, A. L. van Oosten, T. W. Theunissen, G. Guo, J. C. R. Silva, and A. Smith, "Stat3 activation is limiting for reprogramming to ground state pluripotency," Cell Stem Cell, vol. 7, no. 3, pp. 319$328,2010$.

[103] A. L. van Oosten, Y. Costa, A. Smith, and J. C. R. Silva, "JAK/STAT3 signalling is sufficient and dominant over antagonistic cues for the establishment of naive pluripotency," Nature Communications, vol. 3, article 817, 2012.

[104] J. J. Brady, M. Li, S. Suthram, H. Jiang, W. H. Wong, and H. M. Blau, "Early role for IL-6 signalling during generation of induced pluripotent stem cells revealed by heterokaryon RNASeq," Nature Cell Biology, vol. 15, no. 10, pp. 1244-1252, 2013.
[105] H. Wang, J. D. Lathia, Q. Wu et al., "Targeting interleukin 6 signaling suppresses glioma stem cell survival and tumor growth," STEM CELLS, vol. 27, no. 10, pp. 2393-2404, 2009.

[106] R.-H. Chou, Y.-L. Yu, and M.-C. Hung, "The roles of EZH2 in cell lineage commitment," American Journal of Translational Research, vol. 3, no. 3, pp. 243-250, 2011.

[107] K. Xu, Z. J. Wu, A. C. Groner et al., "EZH2 oncogenic activity in castration-resistant prostate cancer cells is plycombindependent," Science, vol. 338, no. 6113, pp. 1465-1469, 2012.

[108] S. J. Morrison and A. C. Spradling, "Stem cells and niches: mechanisms that promote stem cell maintenance throughout life," Cell, vol. 132, no. 4, pp. 598-611, 2008.

[109] J. Luo, S. Ok Lee, L. Liang et al., "Infiltrating bone marrow mesenchymal stem cells increase prostate cancer stem cell population and metastatic ability via secreting cytokines to suppress androgen receptor signaling," Oncogene, vol. 33, no. 21, pp. 2768-2778, 2014.

[110] Y. Zhang, F. Yao, X. Yao et al., "Role of CCL5 in invasion, proliferation and proportion of $\mathrm{CD} 44^{+} / \mathrm{CD} 24^{-}$phenotype of MCF-7 cells and correlation of CCL5 and CCR5 expression with breast cancer progression," Oncology Reports, vol. 21, no. 4, pp. 1113-1121, 2009.

[111] J. Luo, S. O. Lee, C. Yun, R. Yang, and C. Chang, "Infiltrating bone marrow mesenchymal stem cells (BM-MSCs) increase prostate cancer cell invasion via altering the CCL5/HIF2 $\alpha$ /androgen receptor signals," Oncotarget, vol. 6, no. 29, pp. 27555-27565, 2015.

[112] L. Yang, L. Wang, H.-K. Lin et al., "Interleukin-6 differentially regulates androgen receptor transactivation via PI3KAkt, STAT3, and MAPK, three distinct signal pathways in prostate cancer cells," Biochemical and Biophysical Research Communications, vol. 305, no. 3, pp. 462-469, 2003.

[113] C. M. Raynaud, J. M. Butler, N. M. Halabi et al., "Endothelial cells provide a niche for placental hematopoietic stem/progenitor cell expansion through broad transcriptomic modification," Stem Cell Research, vol. 11, no. 3, pp. 1074-1090, 2013.

[114] T. Tumbar, G. Guasch, V. Greco et al., "Defining the epithelial stem cell niche in skin," Science, vol. 303, no. 5656, pp. 359-363, 2004.

[115] A. E. Karnoub, A. B. Dash, A. P. Vo et al., "Mesenchymal stem cells within tumour stroma promote breast cancer metastasis," Nature, vol. 449, no. 7162, pp. 557-563, 2007.

[116] M. Claustres and C. Sultan, "Stimulatory effects of androgens on normal children's bone marrow in culture: effects of BFUE, CFU-E, and uroporphyrinogen I synthase activity," Hormone Research, vol. 23, no. 2, pp. 91-98, 1986.

[117] A. Mantalaris, N. Panoskaltsis, Y. Sakai et al., "Localization of androgen receptor expression in human bone marrow," The Journal of Pathology, vol. 193, no. 3, pp. 361-366, 2001.

[118] P. S. Sullivan, C. W. Jackson, and T. P. McDonald, "Castration decreases thrombocytopoiesis and testosterone restores platelet production in castrated $\mathrm{BALB} / \mathrm{c}$ mice: evidence that testosterone acts on a bipotential hematopoietic precursor cell," The Journal of Laboratory and Clinical Medicine, vol. 125, no. 3, pp. 326-333, 1995.

[119] K.-H. Chuang, S. Altuwaijri, G. Li et al., "Neutropenia with impaired host defense against microbial infection in mice lacking androgen receptor," The Journal of Experimental Medicine, vol. 206, no. 5, pp. 1181-1199, 2009.

[120] C.-K. Huang, K.-P. Lai, J. Luo et al., "Loss of androgen receptor promotes adipogenesis but suppresses osteogenesis in bone 
marrow stromal cells," Stem Cell Research, vol. 11, no. 2, pp. 938950, 2013.

[121] C.-K. Huang, S. O. Lee, K.-P. Lai et al., "Targeting androgen receptor in bone marrow mesenchymal stem cells leads to better transplantation therapy efficacy in liver cirrhosis," Hepatology, vol. 57, no. 4, pp. 1550-1563, 2013.

[122] R. Jasuja, D. H. Catlin, A. Miller et al., "Tetrahydrogestrinone is an androgenic steroid that stimulates androgen receptormediated, myogenic differentiation in $\mathrm{C} 3 \mathrm{H} 10 \mathrm{~T} 1 / 2$ multipotent mesenchymal cells and promotes muscle accretion in orchidectomized male rats," Endocrinology, vol. 146, no. 10, pp. 44724478, 2005.

[123] A. A. Semirale, X.-W. Zhang, and K. M. Wiren, "Body composition changes and inhibition of fat development in vivo implicates androgen in regulation of stem cell lineage allocation," Journal of Cellular Biochemistry, vol. 112, no. 7, pp. 1773-1786, 2011.

[124] K. Brännvall, N. Bogdanovic, L. Korhonen, and D. Lindholm, "19-Nortestosterone influences neural stem cell proliferation and neurogenesis in the rat brain," The European Journal of Neuroscience, vol. 21, no. 4, pp. 871-878, 2005. 

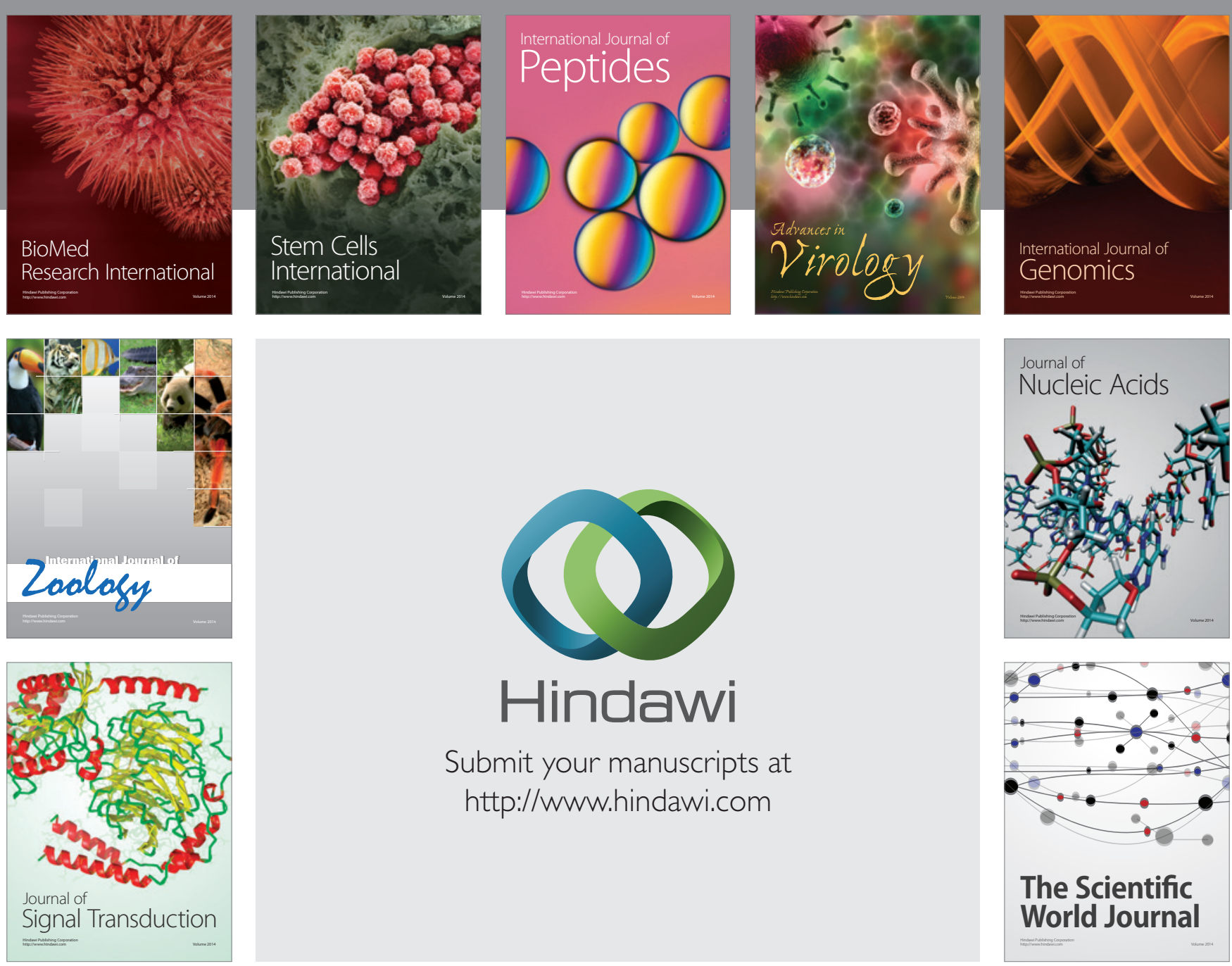

Submit your manuscripts at

http://www.hindawi.com
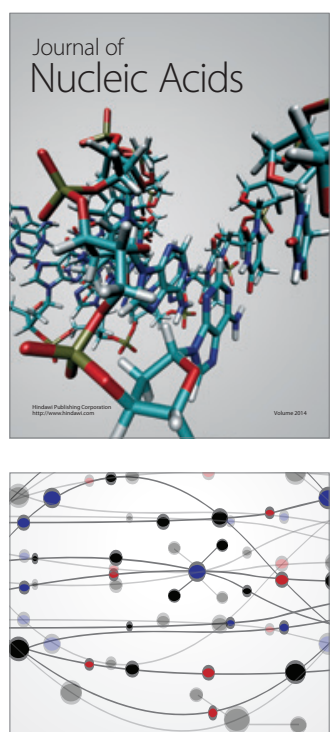

The Scientific World Journal
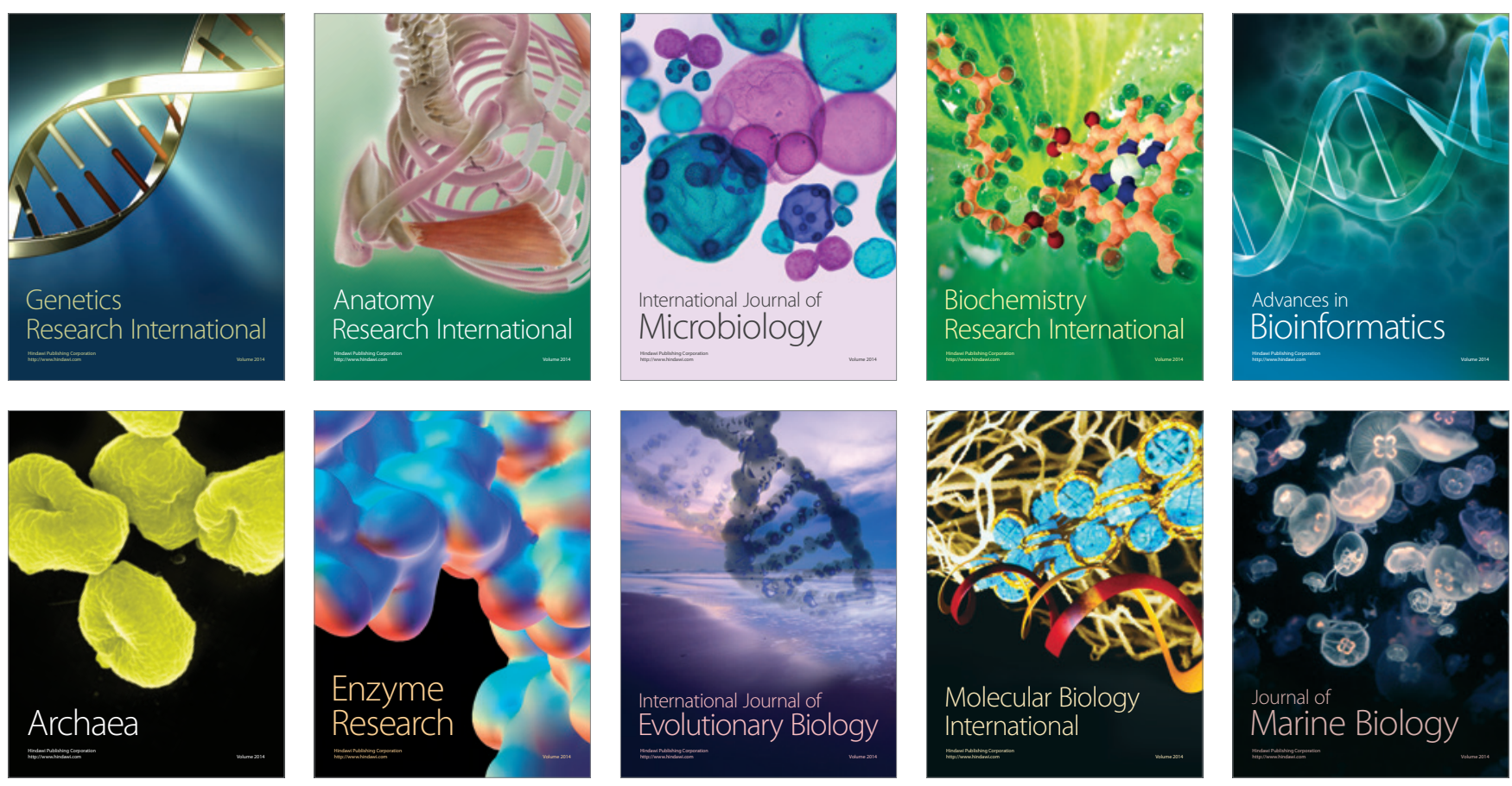